\title{
$\mathrm{BDMI}^{+}$양이온을 함유한 이온성 액체로부터 흑연으로의 전기화학적 리튬 삽입
}

\author{
이유신 · 정순기*· 이헌영 ${ }^{\dagger}$ 김지수 ${ }^{\dagger}$ \\ 순천향대학교 나노화학공학과, ‘주식회사 이아이지
}

\section{Electrochemical Lithium Intercalation within Graphite from Ionic Liquids containing $\mathrm{BDMl}^{+}$Cation}

\author{
You-Shin Lee and Soon-Ki Jeong*, Heon-young Lee ${ }^{\dagger}$, and Chisu Kim ${ }^{\dagger}$ \\ Department of Chemical Engineering, Soonchunhyang University, Asan, Chungnam 336-745, Republic of Korea \\ ${ }^{\dagger} R \& D$ Center, EIG Ltd., Cheonan, Chungnam 330-814, Republic of Korea
}

(Received July 15, 2010 : Accepted July 22, 2010)

\begin{abstract}
초 록
흑연과 1-buthyl-2,3-dimethylimidazolium(BDMI)계 이온성 액체의 계면 반응을 이해하기 위하여 lithium bis(fluorosulfonyl)imide(LiTFSI)가 용해된 BDMI-TFSI 용액 중에서 전기화학 원자간력 현미경(electrochemical atomic force microscopy, ECAFM)을 이용하여 순환 전압전류법 전후에 있어서의 고배향성 열분해 흑연(highly oriented pyrolytic graphite, $\mathrm{HOPG}$ )의 표면을 in-situ로 관찰하였다. $\mathrm{HOPG}$ 전극에서 리튬의 가역적인 삽입과 탈리반응은 진행되지 않았으며, $\mathrm{BDMI}^{+}$ 양이온의 삽입에 의한 blister의 형성 및 그라펜 층의 파괴만이 관찰되었다. 한편, $\mathrm{BDMI}^{+}$양이온의 삽입 반응은 농도가 $4.90 \mathrm{~mol} / \mathrm{kg}$ 인 LiTFSI-propylene carbonate(PC)를 $15 \mathrm{wt} \%$ 함유하고 있는 BDMI-TFSI계에서는 일어나지 않았으며, 이 경우에는 가역적인 리튬의 삽입과 탈리반응이 진행 되었다. ECAFM 결과는 고농도의 $\mathrm{PC}$ 계 용액이 solid electrolyte interface(SEI)를 형성함으로 인해 $\mathrm{BDMI}^{+}$양이온의 삽입을 막는 매우 효과적인 첨가제임을 나타내었다.

Abstract : In situ electrochemical atomic force microscopy (ECAFM) observations of the surface of highly oriented pyrolytic graphite (HOPG) was performed before and after cyclic voltammetry in lithium bis(fluorosulfonyl)imide (LiTFSI) dissolved in 1-buthyl-2,3-dimethylimidazolium (BDMI)TFSI to understand the interfacial reactions between graphite and BDMI-based ionic liquids. The formation of blisters and the exfoliation of graphene layers by the intercalation of $\mathrm{BDMI}^{+}$ cations within HOPG were observed instead of reversible lithium intercalation and de-intercalation. On the other hand, lithium ions are reversibly intercalated into the HOPG and de-intercalatied from the HOPG without intercalation of the $\mathrm{BDMI}^{+}$cations in the presence of $15 \mathrm{wt} \%$ of $4.90 \mathrm{~mol} / \mathrm{kg}^{-1}$ LiTFSI dissolved in propylene carbonate (PC). ECAFM results revealed that the concentrated PC-based solution is a very effective additive for preventing $\mathrm{BDMI}^{+}$intercalation through the formation of solid electrolyte interface (SEI).
\end{abstract}

Keywords : Ionic liquid, $\mathrm{BDMI}^{+}$cation, Lithium secondary battery, Graphite negative electrode, Surface film, SEI, ECAFM

\section{1. 서 론}

음이온과 양이온만으로 이루어져 실온을 포함하는 넓은
온도 영역에서 액체 상태로 존재하는 이온성 액체는 잘 타지 않으며 휘발성이 없다는 성질을 가지는데, 이와 같은 이온성 액체를 리튬 이차전지의 전해질로 이용하여 전지의 안전 성을 향상시키려는 시도가 최근 활발하게 진행되고 있다. ${ }^{14)}$

*E-mail: hamin611@sch.ac.kr 
이온성 액체는 양이온과 음이온의 조합에 따라 다양한 종 류가 존재하며 물리화학적 성질 또한 다양한데, 리튬 이차 전지의 분야에서는 1-ethyl-3methylimidazolium(EMI) 양이 온을 함유하는 이온성 액체가 활발하게 검토되고 있다. ${ }^{1-10)}$ 이처럼 $\mathrm{EMI}$ 계의 이온성 액체가 주된 연구 대상이 되고 있 는 이유는 다양한 음이온과 조합하여 융점과 점성이 낮은 이온성 액체를 용이하게 제조할 수 있기 때문이다. 그렇 지만 EMI계의 이온성 액체는 일반적으로 전위창이 매우 좁으며 전기화학적 내환원성이 좋지 않은 것으로 알려져 있으며, ${ }^{11-13)}$ 이것은 첨가제를 사용하거나 또는 $\mathrm{EMI}^{+}$양이 온 및 음이온의 화학적 구조를 변형하는 방법에 의해 어느 정도 개선할 수 있음이 보고되어 있다.,3,7,8)

$\mathrm{EMI}^{+}$양이온의 내환원성을 높이기 위해 제안된 방법 중의 하나는 $\mathrm{EMI}^{+}$양이온의 C-2 위치에 알킬기를 도입 하는 것으로, 5,7$)$ 이 방법에 의해 다양한 음이온과 조합이 가능한 1-buthyl-2,3-dimethylimidazolium(BDMI) 양이온이 합성되었다. ${ }^{14-19)}$ 이렇게 합성된 $\mathrm{BDMI}$ 계 이온성 액체에 리튬 염을 용해시킨 액체의 물리화학적 특성(밀도, 점도, 이온 전도도, 리튬의 배위 구조 등)이 조사되었는데, $11,14,15)$ $\mathrm{BDMI}$ 계 이온성 액체는 $\mathrm{EMI}$ 계 이온성 액체보다도 점도 가 낮으며 리튬 이차전지의 전해질로 사용하는 경우 C-rate 특성은 약간 저하되지만 양극의 열적 안정성은 크게 개 선된다는 것이 보고되어 있다. ${ }^{16-18)}$ 이처럼 적은 예이기는 하지만 $\mathrm{BDMI}$ 계 전해질 자체의 물리화학적 성질 및 양극 에서 진행하는 반응에 미치는 영향에 관해서는 연구가 진행되어 왔지만, 음극에 대한 영향에 관해서는 아직 보 고된 예가 없다.

따라서 본 연구에서는 $\mathrm{BDMI}$ 계 이온성 액체가 가지는 전기화학적 성질의 기초적인 이해를 목적으로, 고배향성 열 분해 흑연(highly oriented pyrolytic graphite, HOPG) 음 극을 모델 전극으로 이용하고 in-situ 전기화학 원자간력 현 미경(electrochemical atomic force microscopy, ECAFM)을 이용하여 음극과 $\mathrm{BDM}$ 계 전해질 계면에서 진행되는 반응을 분석하였다. 본 논문에서는 리틈염이 용해된 $\mathrm{BDMI}$ 계 이 온성 액체 및 여기에 첨가제로서 propylene carbonate(PC) 가 첨가된 계에서의 흑연 음극 반응에 관하여 보고한다.

\section{2. 실 험}

$\mathrm{BDMI}^{+}$양이온과 $\left(\mathrm{CF}_{3} \mathrm{SO}_{2}\right)_{2} \mathrm{~N}^{-}$(bis (trifluoromethanesulfonylimide), $\mathrm{TFSI}^{-}$) 음이온으로 이루어진 BDMI-TFSI 이온성 액체는 Bazito 그룹이 보고한 방법에 ${ }^{11)}$ 근거하여 $\mathrm{BDMIBr}\left(\mathrm{Kanto} \mathrm{Kagaku}, 99 \%\right.$ ) 화합물의 $\mathrm{Br}^{-}$음이온을 LiTFSI(Kishida Chemical Co., lithium battery grade) 화합물의 $\mathrm{TFSI}^{-}$음이온으로 교환하여 제조하였다. 이렇게 제조된 BDMI-TFSI 용액에는 다량의 수분이 함유되어 있기 때문에, 수분을 제거하기 위하여 금속 리틈을 용액
중에 넣어 glove-box(Miwa, MDB-1B + MM3-P60S, dew point $<60^{\circ} \mathrm{C}$ ) 내부에서 30 일간 방치시킨 후에 사용하였 다. 첨가제로 사용한 LiTFSI-PC 용액은 순수한 $\mathrm{PC}$ (Kishida Chemical Co., lithium battery grade)에 다양한 농도의 LiTFSI를 용해시켜 제조하였다. 제조된 BDMI-TFSI 용액 및 LiTFSI-PC 용액의 수분 함량은 Karl-Fischer 수 분 측정기(Kyoto Electronics Manufacturing Co., MKC210 )를 이용하여 $30 \mathrm{ppm}$ 이하인 것을 확인하였다.

흑연 음극에서 진행되는 전기화학 반응을 이해하기 위하 여 실시된 cyclic voltammetry $(\mathrm{CV})$ 는 연구실에서 자체적 으로 제작한 테플론 재질의 3전극 셀을 이용하였다. 작업 전극으로는 HOPG(Advanced Ceramics, ZYH grade)를 사용하였고 기준전극과 상대전극은 리튬호일을 사용하였다.

전기화학 반응에 따른 흑연 음극 표면의 형상변화는 in-situ ECAFM(Molecular Imaging, PicoSPM)을 이용 하여 접촉모드에서 관찰되었다. 여기에 사용된 전기화학 셀은 $\mathrm{CV}$ 측정과 동일하게 $\mathrm{HOPG}$ 를 작업전극으로 하고, 기준전극 및 상대전극에는 리튬호일을 사용하였다. In-situ $\mathrm{ECAFM}$ 측정은 산소와 수분이 제거된 golve box 내에서 실시되었다.

\section{3. 결과 및 고찰}

합성된 $\mathrm{BDMI}$ 계 이온성 액체와 리틈 이차전지의 대표적 음극인 흑연과의 전기화학적인 반응 거동을 확인하기 위 하여, HOPG를 작업전극으로 하고 BDMI-TFSI에 LiTFSI 를 용해시킨 용액을 전해질로 하여 $\mathrm{CV}$ 측정을 실시하였 다. 그 결과를 Fig. 1 에 나타낸다. 1사이클과 2사이클 모두 $0.5 \mathrm{~V}$ 근방에서 환원전류가 흐르기 시작하여 $0 \mathrm{~V}$ 에 이르 기까지 그 값이 증가하고 있으며, $1.7 \sim 2.7 \mathrm{~V}$ 영역에서는 산화전류가 관찰되었다. 이와 같은 $0.5 \sim 0 \mathrm{~V}$ 영역과 $1.7 \sim$

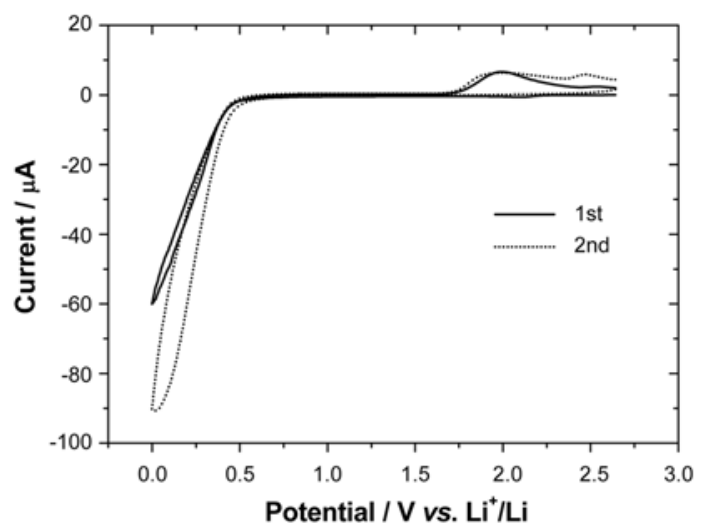

Fig. 1. Cyclic voltammograms of the HOPG basal plane surface in $0.86 \mathrm{~mol} / \mathrm{kg}^{-1}$ LiTFSI dissolved in BDMI-TFSI. Sweep rate: $5 \mathrm{mV} \mathrm{s}^{-1}$. 
$2.7 \mathrm{~V}$ 영역에서 관찰되는 각각의 환원전류 및 산화전류는, 이에 대응하는 산화전류 및 환원전류가 관찰되지 않는 것으로 보아 $\mathrm{HOPG}$ 전극상에서 전해질이 비가역적으로 분해되는 반응에 기인하는 것으로 생각된다. 즉, ethylene carbonate(EC)계 전해질 중에서 안정하게 진행되는 것으 로 알려진 흑연 전극에서의 리튬의 삽입 - 탈리 반응이 $\mathrm{BDMI}$ 계 전해질에서는 진행되지 않는 것을 확인하였다. 전해질 중에 존재하는 리튬 이온이 흑연 내부로 안정되게 삽입되며, 또한 삽입된 리튬 이온이 전해질 중에 가역적 으로 탈리되기 위해서는, 전해질의 분해에 의해 흑연과 전해질의 계면에 solid electrolyte interface(SEI)로 불리는 안정한 표면피막이 반드시 생성되어야 하는 것으로 알려 져 있다. ${ }^{19,20)}$ 따라서 Fig. 1 의 $\mathrm{CV}$ 결과는 $\mathrm{BDMI}$ 계 전해 질이 흑연 전극에 유효한 표면피막을 형성하는 능력을 가지고 있지 않음을 의미한다.

흑연 전극과 $\mathrm{BDMI}$ 계 전해질 계면에서의 반응을 보다 구체적으로 이해하기 위하여, $\mathrm{CV}$ 측정 전후에 있어서의 in-situ ECAFM 분석을 실시하였다. 그 결과를 Fig. 2에 나타낸다. Fig. 2(a)는 전해질 용액과 접촉하고 있는
$\mathrm{HOPG}$ 의 전형적인 표면 형상으로 좌측 상단에서 우측 하 단으로 지나가는 직선적인 step edge가 존재하는 것이 관찰되는데, 이 step edge 부근에서 발생하는 $\mathrm{HOPG}$ 표면 의 형상 변화를 고찰하였다. Fig. 2(b)는 Fig. 1(a)와 동일 한 부분을 1 사이클의 $\mathrm{CV}$ 후에 관찰한 $\mathrm{ECAFM}$ 결과이다. 전극 표면에 전해질의 분해에 의해 생성된 것으로 추 정되는 물질들이 존재하고 있음을 확인할 수 있었다. 이 것은 Fig. 1 의 $\mathrm{CV}$ 에서 관찰되는 $0.5 \sim 0 \mathrm{~V}$ 영역의 환원 반응과 $1.7 \sim 2.7 \mathrm{~V}$ 영역의 산화반응에 의한 것으로 추정 된다. 이렇게 생성된 물질의 조성 및 구체적인 반응기구 에 관해서는 본 연구를 통해 고찰할 수 없었지만, 이것이 유효한 SEI로서의 기능을 가지고 있지 않음은 분명하다. Fig. 2(c)는 Fig. 2(b)에서 관찰되는 전극 표면에 생성된 물질을 $\mathrm{ECAFM}$ 의 탐침을 이용하여 제거한 결과이다. $\mathrm{ECAFM}$ 을 가동시키면서 시료와 탐침 사이에 작용하는 힘을 적절히 제어하면 이처럼 흑연 표면을 덮고 있는 피막을 제거하는 것이 가능하다. ${ }^{21-23)} \mathrm{Fig} .2$ (c)로부터 1사이클 후에 다수의 blister(화살표로 표시된 부분)가 생성되었으 며, 또한 step edge가 부분적으로 파괴되어 있는 것을 확
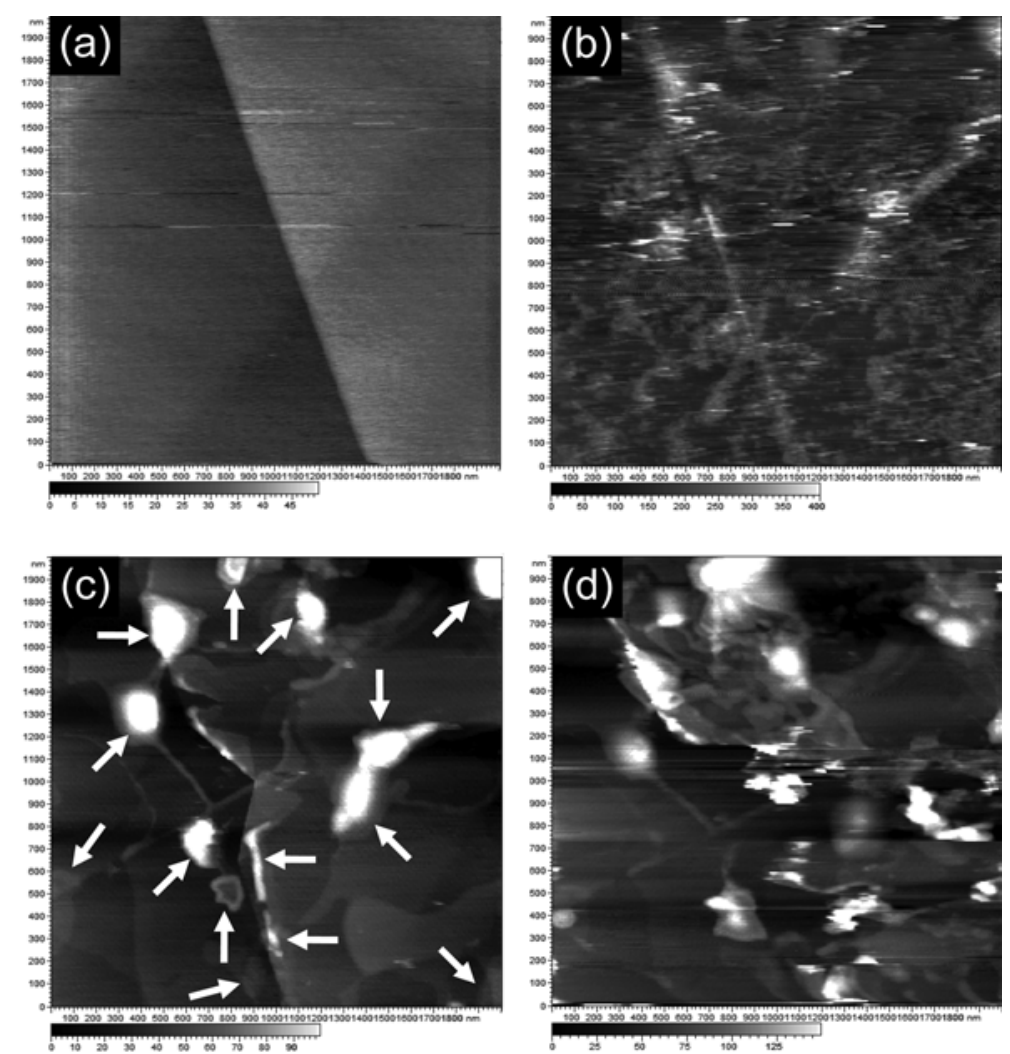

Fig. 2. In-situ ECAFM images $\left(5 \times 5 \mu \mathrm{m}^{2}\right)$ of the HOPG basal plane surface obtained at $2.9 \mathrm{~V}$ in $0.86 \mathrm{~mol} \mathrm{~kg}^{-1}$ LiTFSI dissolved in BDMI-TFSI (a) before and (b, c) after the first cycle of $\mathrm{CV}$, and (d) after the second cycle of $\mathrm{CV}$. 
인할 수 있다. 이러한 blister는 EC계의 전해질을 사용했 을 때 흑연 내부로 $\mathrm{EC}$ 용매가 삽입된 후에 분해되어 생 성되는 것과 매우 유사한 것이다. 따라서 $\mathrm{BDMI}$ 계 전해 질을 사용하였을 경우, $\mathrm{BDMI}^{+}$양이온이 흑연 내부에 삽 입된 후에 이것이 분해되어 Fig. 2(c)의 blister가 생성되 었다고 추정되며, 이 과정에서 일부의 흑연 층은 응력을 이기지 못해 step edge가 파괴되는 현상이 발생한 것으 로 추정된다. Fig. 1의 CV에서 1사이클보다 2사이클 에서 환원전류와 산화전류의 값이 증가한 이유는, 1 사이 클 과정에서 step edge가 파괴됨으로 인해 반응 장소인 전 극의 표면적이 증가했기 때문으로 생각된다. 이와 같은 blister의 생성 및 step edge의 파괴 현상은 2 사이클 중에 도 계속하여 진행되는데 이것은 Fig. 2(d)를 통해 확인할 수가 있다. Fig. 2(d)는 2사이클 후의 표면 형상으로, Fig. 2(c)와 동일한 방법인 ECAFM 탐침의 제어에 의해 전극 표면의 생성물을 제거하여 얻은 결과이다.

EMI계 전해질 중에서는 금속 리튬이 부식되지만, ${ }^{24)}$ 본 연구에서 사용된 $\mathrm{BDMI}$ 계 전해질 중에서는 그러한 부 식은 관찰되지 않았다. 이것은 $\mathrm{EMI}^{+}$양이온의 $\mathrm{C}-2$ 위치 에 알킬기를 도입함으로 인해 내환원성이 증가되었다는 것을 의미한다. 그렇지만 이러한 내환원성의 증가에도 불 구하고, Fig. 1의 CV와 Fig. 2의 ECAFM 결과를 통해 $\mathrm{BDMI}^{+}$양이온이 흑연 내부에 삽입되어 분해되는 비가
역적 산화·환원반응만이 흑연 전극에서 진행하며, 리튬 이온의 가역적인 산환 - 환원반응은 진행하지 않는다는 것이 확인되었다. EMI계 전해질에 관한 최근의 연구에 의하면, Sutto 그룹은 X-선 회절 분석에 의해, ${ }^{25}$ Hardwick 그룹은 in-situ Raman 분석에 의해 ${ }^{26)} \mathrm{EMI}^{+}$양이온이 흑 연 내부로 삽입됨을 보고하고 있다. 즉, $\mathrm{BDMI}^{+}$양이온은 흑연 전극에 대해 $\mathrm{EMI}^{+}$양이온과 유사한 전기화학적 거 동을 나타내는 것이 관찰되었다.

BDMI-TFSI 전해질과 흑연 전극 계면에서 안정된 리튬 의 산화·환원반응이 진행되기 위해서는, 흑연 전극에 안 정한 $\mathrm{SEI}$ 를 형성시킬 필요가 있으며, 이와 같은 목적으로 본 연구에서는 $\mathrm{PC}$ 계 첨가제에 대하여 검토하였다. $\mathrm{PC}$ 는 저온에서도 매우 우수한 리튬이온 전도성을 나타내며, 리튬염의 농도가 낮은 $\mathrm{PC}$ 용액은 $\mathrm{SEI}$ 를 형성하는 능력이 없지만 리틈염의 농도가 높은 경우에는 우수한 $\mathrm{SEI}$ 를 형성한다는 것이 $\mathrm{LiN}\left(\mathrm{SO}_{2} \mathrm{C}_{2} \mathrm{~F}_{5}\right)_{2}$ - $\mathrm{PC}$ 계 전해질에 대해서 보고되어 있다. ${ }^{22)}$ 본 연구에서는 $\mathrm{LiN}\left(\mathrm{SO}_{2} \mathrm{C}_{2} \mathrm{~F}_{5}\right)_{2}$ 와 비슷한 구조를 가지는 $\mathrm{LiN}\left(\mathrm{SO}_{2} \mathrm{CF}_{3}\right)_{2}$ 을 리튬염으로 이용하였으며, 이 리튬염의 적절한 농도를 결정하기 위하여 다양한 농 도의 $\mathrm{PC}$ 계 용액을 제조한 후, $\mathrm{HOPG}$ 전극의 $\mathrm{CV}$ 측정을 통해 각 용액의 $\mathrm{SEI}$ 형성 능력을 확인하였다. 그 결과를 Fig. 3에 나타낸다. Fig. 3(a)는 $1.63 \mathrm{~mol} / \mathrm{kg}$ 의 저농도 용액 중에서 얻어진 $\mathrm{CV}$ 결과로 리튬의 산화·환원반응에 귀
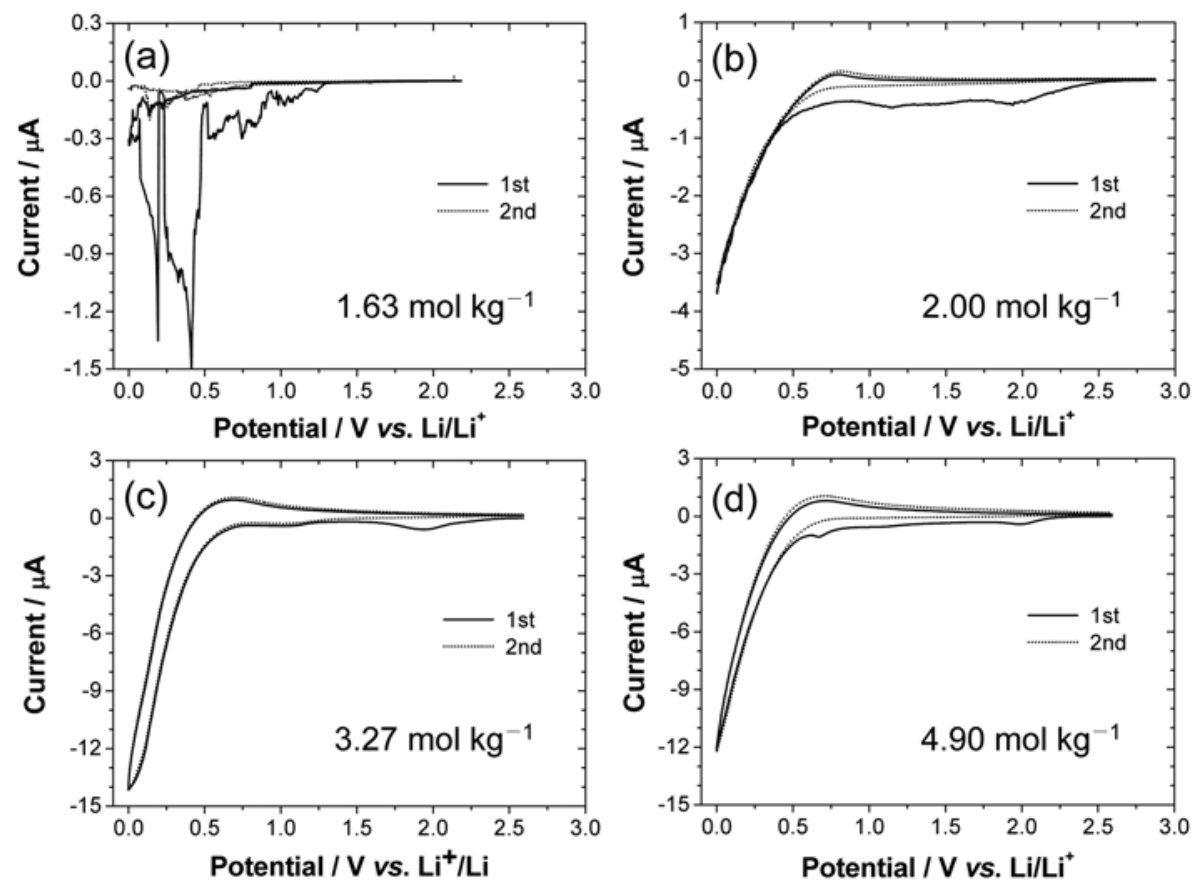

Fig. 3. Cyclic voltammograms of the HOPG basal plane surface in various concentration of LiTFSI dissolved in PC. Sweep rate: $0.5 \mathrm{mV} \mathrm{s}^{-1}$. 
속되는 피크가 관찰되지 않으며, 이를 통해 흑연 전극 표 면에 SEI가 형성되지 않은 것을 알 수 있다. 이와는 대조적 으로 $2.00,3.27,4.90 \mathrm{~mol} / \mathrm{kg}$ 용액 중에서는 $\mathrm{HOPG}$ 내부 로 리튬이 삽입되는 반응에 귀속되는 $0 \mathrm{~V}$ 부근의 환원전 류와 리튬의 탈리에 귀속되는 $0.6 \mathrm{~V}$ 부근의 산화전류가 관찰되었고, ${ }^{27,28)}$ 그 가역성이 농도가 커짐에 따라 좋아지고 있어, 고농도의 전해질일수록 SEI 형성 능력이 우수함을 확인할 수 있었다. $\mathrm{CV}$ 와 연동된 $\mathrm{ECAFM}$ 측정의 경우, $5 \mathrm{mV} / \mathrm{s}$ 의 전위 주사 속도로 반응을 진행시킨 것에 대해, Fig. 3에서는 $0.5 \mathrm{mV} / \mathrm{s}$ 의 속도로 전위를 주사하였다. 그 이유는 $\mathrm{PC}$ 계 용액 중에서 빠른 속도로 전위를 주사하면 리튬의 삽입 반응과 SEI 형성 외에도 용매화된 리튬의 공삽입 반응이 진행하여, SEI 형성 과정에 관한 해석을 어렵게 하기 때문이다. ${ }^{29}$ 따라서 Fig. 3 에서는 전위 주사 속도를 느리게 하여 여러 종류의 $\mathrm{PC}$ 계 전해질 중에서 진 행되는 SEI 형성 반응에 관한 정보를 얻었다. 또한, 본 연구에서 사용된 ECAFM 장치는 Fig. 3에서와 같은 $0.5 \mathrm{mV} / \mathrm{s}$ 의 전위 주사 속도로는 $\mathrm{CV}$ 가 작동을 하지 않는 다는 장치 사양의 한계가 있어, Fig. 1과 Fig. 3, 그리고 이후에 설명하는 Fig. 4에서 다른 전위 주사 속도가 이 용되었지만, 보다 정확한 해석을 위해서는 향후 동일한 주사 속도에서 측정할 필요가 있다고 생각한다.

본 연구에서는 SEI 형성 능력이 가장 우수한 $4.90 \mathrm{~mol} / \mathrm{kg}$ 의 $\mathrm{LiN}\left(\mathrm{SO}_{2} \mathrm{CF}_{3}\right)_{2}$ 가 용해 된 $\mathrm{PC}$ 용액을 첨가제로 사용 하였다. 이 농도는 $\mathrm{PC}$ 에 용해될 수 있는 $\mathrm{LiN}\left(\mathrm{SO}_{2} \mathrm{CF}_{3}\right)_{2}$ 의 최대치에 가까운 양이며, 이 용액을 첨가제로 사용한 경우의 $\mathrm{CV}$ 결과를 Fig. 4에 나타낸다. 리틈의 삽입 반응 과 탈리 반응에 기인하는 환원전류와 산화전류가 각각 $0 \mathrm{~V}$ 와 $0.6 \mathrm{~V}$ 부근에서 관찰되었다. 또한 1 사이클의 $0.5 \mathrm{~V}$ 부근에서 관찰되는 비가역적 환원전류가 2 사이클에서는 관찰되지 않는데, 이것은 이 전류가 SEI 형성에 사용된 것을 의미한다. 즉, $\mathrm{BDMI-TFSI는} \mathrm{SEI}$ 형성 능력을 가지 지 않지만, $\mathrm{SEI}$ 형성제로 첨가된 고농도의 $\mathrm{PC}$ 용액이 유

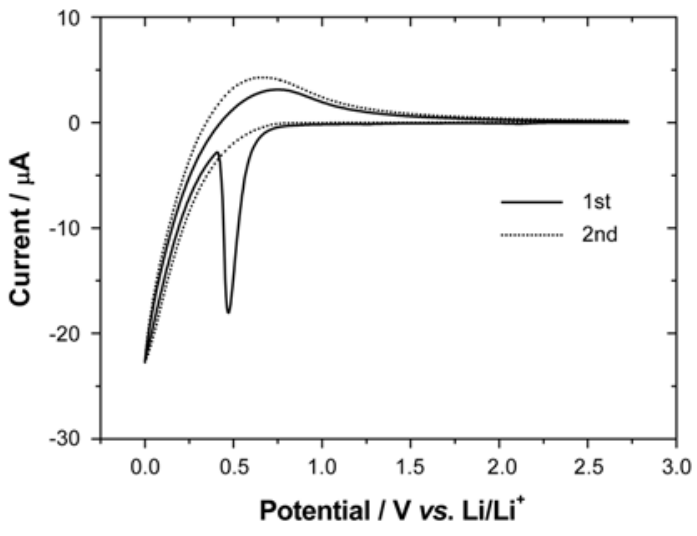

Fig. 4. Cyclic voltammograms of the HOPG basal plane surface in BDMI-TFSI containing $15 \mathrm{wt} \%$ additive. Additive: $4.90 \mathrm{~mol} / \mathrm{kg}^{-1}$ LiTFSI dissolved in PC. Sweep rate: $5 \mathrm{mV} \mathrm{s}^{-1}$.

효하게 기능하고 있음을 확인할 수 있었다. 또한, Fig. 3(d) 에서는 SEI 형성과 관련된 작은 피크가 $0.7 \mathrm{~V}$ 부근에서 관찰되는 것에 비해, Fig. 4 의 이온성 액체 중에서는 $0.5 \mathrm{~V}$ 부근에서 나타나고 있다. 이에 관한 이유는 정확히 알 수 없으나, 한 가지 추정할 수 있는 것은 용액 중에 존재하 는 리튬 이온의 주변 환경이 달라진 것이 원인으로 생각 된다. 즉, 리틈 이온은 $\mathrm{PC}$ 분자에 의해 용매화된 상태로 전해질 중에 존재하고 이것이 분해되어 $\mathrm{SEI}$ 를 형성하게 되는데, 이러한 용매화된 리튬 이온의 전자 상태가 주변 의 $\mathrm{BDMI}^{+}$양이온에 의해 영향을 받아 분해 거동이 달 라진 것으로 추정된다.

고농도의 $\mathrm{PC}$ 용액에 의해 생성되는 $\mathrm{SEI}$ 의 구체적인 이 해를 목적으로 $\mathrm{CV}$ 측정 전후에 있어서의 in-situ ECAFM 분석을 실시하였으며, 그 결과를 Fig. 5에 나타낸다. 1사 이클의 $\mathrm{CV}$ 후에 전해질의 분해 생성물로 추정되는 물질 이 전극 표면 전체를 덮고 있는 것을 Fig. 5(b)로부터 알
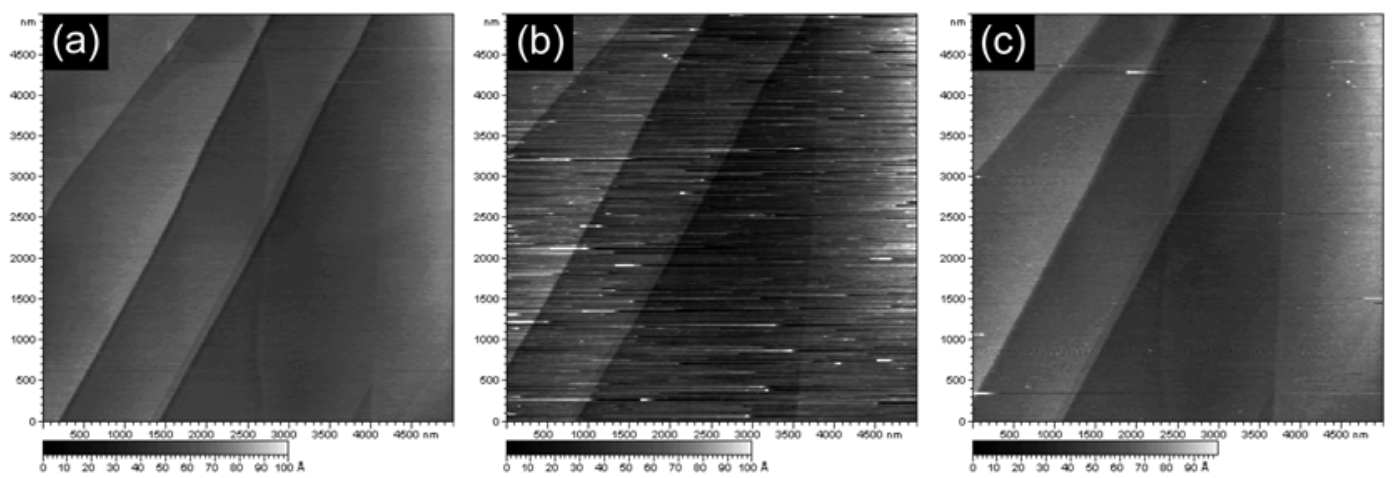

Fig. 5. In-situ ECAFM images $\left(5 \times 5 \mu \mathrm{m}^{2}\right)$ of the HOPG basal plane surface obtained at $2.9 \mathrm{~V}$ (a) before and (b, c) after the first cycle of CV in BDMI-TFSI containing $15 \mathrm{wt} \%$ of $4.90 \mathrm{~mol} \mathrm{~kg}{ }^{-1}$ LiTFSI dissolved in PC. 
수 있다. 첨가제가 들어있지 않은 $\mathrm{BDMI}$ 계 전해질 중에서 Fig. 2(c)와 Fig. 2(d)의 ECAFM 결과를 얻은 것과 동일 한 방법으로 Fig. 5(b)에서 관찰되는 전극 표면의 물질을 제거하면 Fig. 5(c)가 얻어진다. 이 결과는 첨가제가 함유 되지 않은 전해질 중에서 얻은 결과인 Fig. 2(c)와는 매우 다른 표면 형상을 나타내었다. Fig. 2(c)에서 관찰되는 blister와 step edge의 파괴가 Fig. 5(c)에서는 전혀 관찰되 지 않았다. 이것은 Fig. 5(b)에서 관찰되는 전극 표면을 덮고 있는 물질들이, $\mathrm{BDMI}^{+}$양이온이 흑연 내부로 삽 입되는 것을 막는 동시에 선택적으로 리틈 이온만 통과 시키는 유효한 SEI로서 작용하고 있다는 것을 의미한다. 즉, Fig. 1을 통해 알 수 있듯이 $\mathrm{BDMI}^{+}$양이온은 $0.5 \mathrm{~V}$ 부근에서 흑연 전극과 반응하는데, Fig. 4에서와 같 이 $\mathrm{PC}$ 계의 첨가제가 분해되어 $\mathrm{SEI}$ 를 형성하기 시작하는 것은 그보다 높은 $0.7 \mathrm{~V}$ 부근이기 때문에, $\mathrm{BDMI}^{+}$양이온 의 반응에 앞서서 SEI가 형성되었고, 이로 인해 리튬 이온 의 안정된 삽입·탈리반응이 진행되는 것으로 생각된다.

Fig. 4와 Fig. 5에 사용된 첨가제는 $4.90 \mathrm{~mol}$ 의 $\mathrm{LiN}$ $\left(\mathrm{SO}_{2} \mathrm{CF}_{3}\right)_{2}$ 가 $1 \mathrm{~kg}$ 의 PC에 용해된 용액으로, 이것이 BDMI$\mathrm{TFSI}$ 용액에 $15 \mathrm{w} \%$ 첨가되었을 경우에는 $\mathrm{BDMI-TFSI}$ 와 $\mathrm{PC}$ 를 용매로, $\mathrm{LiN}\left(\mathrm{SO}_{2} \mathrm{CF}_{3}\right)_{2}$ 를 용질로 간주할 수 있으며, 따라서 $1 \mathrm{~kg}$ 의 BDMI-TFSI-PC 용매에 대해 $\mathrm{LiN}\left(\mathrm{SO}_{2} \mathrm{CF}_{3}\right)_{2}$ 의 농도는 $0.34 \mathrm{~mol}$ 의 작은 값을 가지게 된다. 그럼에도 불구하고 유효한 첨가제로서 작용하는 이유는 리틈 이온 과 $\mathrm{PC}$ 분자의 몰비에 의해 설명할 수 있다. 즉, $\mathrm{SEI}$ 의 생성 반응은 용액 중에 존재하는 리튬 이온과 $\mathrm{PC}$ 분자의 몰비 에 크게 영향을 받는 것으로 보고되어 있는데, ${ }^{22,30)}$ 본 연 구에서 사용된 첨가제인 $4.90 \mathrm{~mol} / \mathrm{kg} \mathrm{LiN}\left(\mathrm{SO}_{2} \mathrm{CF}_{3}\right)_{2} / \mathrm{PC}$ 에서의 리튬 이온과 $\mathrm{PC}$ 분자의 몰비는 $1: 2$ 로 이러한 몰 비가 이온성 액체 중에서도 동일하게 유지되기 때문에 첨가제로서의 기능을 발현한 것으로 추정된다.

\section{4. 결 론}

본 연구에서는 $\mathrm{BDMI}$ 계의 이온성 액체와 흑연 전극의 계면에서 일어나는 전기화학 반응에 관하여 고찰하였다. 흑연을 음극으로 이용하는 리튬 이차전지의 전해질로 사 용되기 위해서는, 전극 반응의 초기에 전해질이 분해되며 전극 표면에 안정한 $\mathrm{SEI}$ 가 생성되는 것이 필수적인데, LiTFSI가 용해된 BDMI-TFSI 전해질 중에서는 그와 같은 $\mathrm{SEI}$ 의 생성 반응이 진행되지 않는다는 것이 확인되었다. 따라서 전극 반응의 주체가 되어야 하는 가역적인 리튬 이온의 산화-환원반응 또한 진행하지 않으며, 비가역적 반응인 $\mathrm{BDMI}^{+}$양이온이 흑연 내부에 삽입되며 발생하는 blister의 생성 및 흑연 전극의 파괴만이 확인되었다. 이와 같은 비가역적 반응은 고농도의 LiTFSI-PC 용액을 첨가 제로 이용하여 막을 수 있음이 확인되었다. 아울러 그러한
$\mathrm{PC}$ 계의 첨가제는 리튬 이온의 가역적인 산화 - 환원 반응을 가능하게 해주었다.

\section{감사의 글}

본 논문은 2008년 중소기업청에서 지원하는 산학협력실 지원사업 중대형 리튬이차전지용 고안전성 전해질의 개발 과제의 결과물입니다.

\section{참고문헌}

1. W. Xu, J. Xiao, D. Wang, J. Zhang, and J.-G. Zhang, 'Effects of nonaqueous electrolytes on the performance of lithium/ air batteries' J. Electrochem. Soc., 157, A219 (2010).

2. Y. Fu, C. Chen, C. Qiu, and X. Ma, 'Vinyl ethylene carbonate as an additive to ionic liquid electrolyte for lithium ion batteries' J. Appl. Electrochem., 39, 2597 (2009).

3. T. Sugimoto, M. Kikuta, E. Eshiko, M. Kono, and M. Ishikawa, 'Ionic liquid electrolytes compatible with graphitized carbon negative without additive and their effects on interfacial properties' J. Power Sources, 183, 436 (2008).

4. L. J. Hardwick, P. W. Ruch, M. Hahn, W. Scheifele, R. Kötz, and P. Novak, 'In situ Raman spectroscopy of insertion electrodes for lithium-ion batteries and supercapacitors: First cycle effects' J. Physics and Chemistry of Solids, 69, 1232 (2008)

5. S. Seki, Y. Ohno, Y. Kobayashi, H. Miyashiro, A. Usami, Y. Mita, H. Tokuda, M. Watanabe, K. Hayamizu, S. Tsuzuki, M. Hattori, and B. Terada, 'Imidazolium-based room-temperature ionic liquid for lithium secondary batteries' J. Electrochem. Soc., 154, A173 (2007).

6. M. Holzapfel, C. Jost, A. Prodi-Schwab, F. Krumeich, A. Würsig, H. Buqa, and P. Novak, 'Stabilization of lithiated graphite in an electrolyte based on ionic liquids: an electrochemical and scanning electron microscopy study' Carbon, 43, 1488 (2005).

7. K. Hayashi, Y. Nemoto, K. Akuto, and Y. Sakurai, 'Alkylated imidazolium salt electrolyte for lithium cells' J. Power Sources, 146, 689 (2005).

8. M. Holzapfel, C. Jost, and P. Novak, 'Stable cycling of graphite in an ionic based electrolyte' Chem. Commun., 2098 (2004).

9. B. Garcia, S. Lavallee, G. Perron, C. Michot, and M. Armand, 'Room temperature molten salts as lithium battery electrolyte' Electrochimica Acta, 49, 4583 (2004).

10. A. B. McEwen, H. L. Ngo, K. LeCompte, and J. L. Goldman, 'Electrochemical properties of imidazolium salt electrolytes for electrochemical capacitor applications' $J$. Electrochem. Soc., 146, 1687 (1999).

11. F. F. C. Bazito, Y. Kawano, and R. M. Torresi, 'Synthesis and characterization of two ionic liquids with emphasis on their chemical stability towards metallic lithium' 
Electrochimica Acta, 52, 6427 (2007).

12. J. Fuller, R. T. Carlin, and R. A. Osteryoung, 'The room temperature ionic liquid 1-ethyl-3-methylimidazolium tetrafluoroborate: electrochemical couples and physical properties' J. Electrochem. Soc., 144, 3881 (1997).

13. V. R. Koch, C. Nanjundiah, G. B. Appetecch, and B. Scrosati, 'The interfacial stability of $\mathrm{Li}$ with two new solvent-free ionic liquids: 1,2-dimethly-3-propylimidazolium imide and methide' J. Electrochem. Soc., 142, L116 (1995).

14. M. J. Monteiro, F. F. C. Bazito, and L. J. A. Siqueira, 'Transport coefficients, Raman spectroscopy, and computer simulation of lithium salt solutions in an ionic liquid' $J$. Phys. Chem. B, 112, 2102 (2008).

15. Y. Saito, T. Umecky, U. Niwa, T. Sakai, and S. Maeda, 'Existing condition and migration property of ions in lithium electrolytes with ionic liquid solvent' J. Phys. Chem. B, 111, 11794 (2007).

16. Y. Yang, K. Zaghib, A. Guerfi, F. F. C. Bazito, R. M. Torresi, and J. R. Dahn, 'Accelerating rate calorimetry studies of the reactions between ionic liquids and charged lithium ion battery electrode materials' Electrochimica Acta, 52, 6346 (2007).

17. S. Lee, H. Yong, S. Kim, J. Kim, and S. Ahn, 'Performance and thermal stability of $\mathrm{LiCoO}_{2}$ cathode modified with ionic liquid' J. Power Sources, 146, 732 (2005).

18. S. Lee, H. Yong, Y. Lee, S. Kim, and S. Ahn, 'Two-cation competition in ionic-liquid-modified electrolytes for lithium ion batteries' J. Phys. Chem. B, 109, 13663 (2005).

19. R. Yazami and D. Guerard, 'Some aspects on the preparation, structure and physical and electrochemical properties of $\mathrm{Li}_{\mathrm{x}} \mathrm{C}_{6}{ }^{\prime}$ J. Power Sources, 43-44, 39 (1993).

20. E. Peled, 'The electrochemical behavior of alkali and alkaline earth metals in nonaqueous battery systems? The solid electrolyte interphase Model' J. Electrochem. Soc., 126, 2047 (1979).

21. H. X. You, J. M. Lau, S. Zhang, and L. Yu, 'Atomic force microscopy imaging of living cells: a preliminary study of the disruptive effect of the cantilever tip on cell morphology' Ultramicroscopy, 82, 297 (2000).
22. S.-K. Jeong, M. Inaba, Y. Iriyama, T. Abe and Z. Ogumi, 'Interfacial reactions between graphite electrodes and propylene carbonate-based solutions: electrolyte-concentration dependence of electrochemical lithium intercalation reaction' J. Power Sources, 175, 540 (2008)

23. S.-K. Jeong, M. Inaba, T. Abe, and Z. Ogumi, 'Surface film formation on graphite negative electrode in lithiumion batteries: AFM study in an ethylene carbonate-based solution' J. Electrochem. Soc., 148, A989 (2001).

24. V. R. Koch, C. Nanjundiah, G. B. Appetecchi, and B. Scrosati, 'The interfacial stability of $\mathrm{Li}$ with two new solventfree ionic liquids: 1,2-Dimethyl-3-propylimidazolium imide and methide' J. Electrochem. Soc., 142, L116 (1995).

25. T. E. Sutto, T. T. Duncan, and T. C. Wong, 'X-ray diffraction studies of electrochemical graphite intercalation compounds of ionic liquids' Electrochimica Acta, 54, 5648 (2009).

26. L. L. Hardwick, P. W. Ruch, M. Hahn, W. Scheifele, R. Kotz, and P. Novak, 'In-situ Raman spectroscopy of insertion electrodes for lithium-ion batteries and supercapacitors: First cycle effects' J. Physics and Chemisty of Solids, 69, 1232 (2008).

27. T. Tran and K. Kinoshita, 'Lithium intercalation deintercalation behavior of basal and edge planes of highly oriented pyrolytic-graphite and graphite powder' $J$. Electroanal. Chem., 386, 221 (1995).

28. A. Funabiki, M. Inaba, and Z. Ogumi, 'AC impedance analysis of electrochemical lithium intercalation into highly oriented pyrolytic graphite' J. Power Sources, 68, 227 (1997).

29. M. R. Wagner, J. H. Albering, K. -C. Moeller, J. O. Besenhard, and $\mathrm{M}$. Winter 'XRD evidence for the electrochemical formation of $\mathrm{Li}^{+}(\mathrm{PC})_{y} \mathrm{C}_{n}^{-}$in PC-based electrolytes' Electrochemistry Communications, 7, 947 (2005).

30. Y. Yamada, Y. Koyama, T. Abe, and Z. Ogumi, 'Correlation between charge-discharge behavior of graphite and solvation structure of the lithium ion in propylene carbonatecontaining electrolytes' J. Phys. Chem. C, 113, 8948 (2009). 